\title{
"Homogeneous" second order differential equation: zeros separation principles
}

\author{
Ioan A. Rus
}

Abstract. In this paper we study the following problems:

Problem 1. Let $I \subset \mathbb{R}$ be an open interval and $F: \mathbb{R}^{3} \times I \rightarrow \mathbb{R}$ be a continuous function with, $F(0,0,0, x)=0$, for all $x \in I$. We consider the following differential equations

$$
F\left(y^{\prime \prime}, y^{\prime}, y, x\right)=0 \text {. }
$$

Let $y \in C^{2}(I)$ be a nontrivial solution of (0.1). In which conditions we have that:

(1) the zeros of $y$ and $y^{\prime}$ separate each other?

(2) the zeros of $y$ and $y^{\prime \prime}$ separate each other?

(3) the zeros of $y^{\prime}$ and $y^{\prime \prime}$ separate each other?

Problem 2. Let $y_{1}, y_{2} \in C^{2}(I)$ be two linearly independent solutions of (0.1).

In which conditions we have that:

(1) the zeros of $y_{1}$ and $y_{2}$ separate each other?

(2) the zeros of $y_{1}^{\prime}$ and $y_{2}^{\prime}$ separate each other?

(3) the zeros of $y_{1}^{\prime \prime}$ and $y_{2}^{\prime \prime}$ separate each other?

$\underline{\text { Problem 3 }}$. Let $F, G: \mathbb{R}^{3} \times I \rightarrow \mathbb{R}$ be two continuous functions with $F(0,0,0, x)=0$, $\overline{G(0,0,0, x)}=0$, for all $x \in I$. We consider the following system of differential equations,

$$
\begin{aligned}
& F\left(y^{\prime}, y, z, x\right)=0, \\
& G\left(z^{\prime}, y, z, x\right)=0 .
\end{aligned}
$$

Let $(y, z) \in C^{1}\left(I, \mathbb{R}^{2}\right)$ be a nontrivial solution of $(0.2)$. In which conditions we have that:

(1) the zeros of $y$ and $z$ separate each other?

(2) the zeros of $y^{\prime}$ and $z^{\prime}$ separate each other?

Problem 4 . Let $\left(y_{1}, z_{1}\right)$ and $\left(y_{2}, z_{2}\right)$ be two linearly independent solutions of (0.2). In which conditions we have that:

(1) the zeros of $y_{1}$ and $y_{2}$ separate each other?

(2) the zeros of $z_{1}$ and $z_{2}$ separate each other?

(3) the zeros of $y_{1}^{\prime}$ and $y_{2}^{\prime}$ separate each other?

(4) the zeros of $z_{1}^{\prime}$ and $z_{2}^{\prime}$ separate each other?

Some other problems are formulated. 
Mathematics Subject Classification (2010): 34C10, 12D10, 34B24, 33xx, 34M10.

Keywords: Second order differential equation, first order system of differential equations, zero separation, Sturm theorem, Nicolescu theorem, Butlewski theorem, Markov theorem, zeros of special functions defined by differential equations, zero distance function, functions defined in terms of zeros of solutions, equation in the complex domain, computation of zeros by fixed point techniques, categories of linear differential equations.

\section{Introduction and Preliminaries}

Let $I \subset \mathbb{R}$ be an open interval (bounded or not!) of $\mathbb{R}$. For a function $y: I \rightarrow \mathbb{R}$ we denote by $Z_{y}$ the zero set of $y$.

Definition 1.1. The zeros of two functions $y_{1}, y_{2} \in C(I)$ separate each other iff:

(1) $Z_{y_{1}} \cap Z_{y_{2}}=\emptyset$;

(2) all zeros of $y_{1}$ and $y_{2}$ are simple;

(3) if $x_{1}$ and $x_{2}$ are two consecutive zeros of $y_{1}$, then $y_{2}$ has one zero in $] x_{1}, x_{2}$ [, and if $x_{1}, x_{2}$ are two consecutive zeros of $y_{2}$, then $y_{1}$ has one zero in $] x_{1}, x_{2}[$.

The following results are well known:

Wronskian Lemma $(1962 ;[49],[54],[8])$. Let $y_{1}, y_{2} \in C^{1}(I)$ be two functions. If

$$
W\left(y_{1}, y_{2}\right)(x):=\left|\begin{array}{ll}
y_{1} & y_{2} \\
y_{1}^{\prime} & y_{2}^{\prime}
\end{array}\right|(x) \neq 0, \text { for all } x \in I,
$$

then the zeros of $y_{1}$ and $y_{2}$ separate each other.

Tonelli Lemma (1963; [50], [63], [39], [28]). Let $y_{1}, y_{2} \in C^{1}[a, b]$ be such that

(1) $y_{1}(a)=y_{1}(b)=0$ and $y_{1}(x)>0$, for all $\left.x \in\right] a, b[$;

(2) $y_{2}(x)>0$, for all $x \in[a, b]$.

Then there exist $\left.x_{0} \in\right] a, b[$ and $\lambda>0$ such that:

(i) $y_{2}\left(x_{0}\right)=\lambda y_{1}\left(x_{0}\right)$;

(ii) $y_{2}^{\prime}\left(x_{0}\right)=\lambda y_{1}^{\prime}\left(x_{0}\right)$.

Let $F, G: \mathbb{R}^{3} \times I \rightarrow \mathbb{R}$ be two continuous functions with $F(0,0,0, x)=0$, $G(0,0,0, x)=0$, for all $x \in I$. We consider the following differential equation

$$
F\left(y^{\prime \prime}, y^{\prime}, y, x\right)=0
$$

and the following differential system

$$
\begin{aligned}
& F\left(y^{\prime}, y, z, x\right)=0 \\
& G\left(z^{\prime}, y, z, x\right)=0
\end{aligned}
$$

There are many results for the zeros of the solutions $y \in C^{2}(I)$ of (1.1) and of the components $y$ and $z$ of the solutions $(y, z) \in C^{1}\left(I, \mathbb{R}^{2}\right)$ of $(1.2)$ (see the books: [57], [58], [24], [25], [47], [61], [2], [4], [6], [10], [13], [15], [22], [23], [26], [27], [30], [31], [32], 
[34], [35], [40], [41], [45], [55], [62], [64], [68], [17], .. and articles: [1], [3], [5], [7], [8], [14], [16]-[21], [28], [37], [39], [42], [43], [48]-[54], [63], ...).

In this paper we present new results, new proofs for some known results by techniques of real function theory: Bolzano Theorem, Rolle Theorem, Wronskian Lemma and Tonelli Lemma. Some research directions are also presented.

The structure of our paper is as follows:

2. Zeros separation of some real functions

3. Linear and homogeneous second order differential equations

4. Nonlinear equations in a normal form

5. Homogeneous nonlinear second order differential equations

6. Some research directions

\section{Zeros Separation of Some Real Functions}

Let $I \subset \mathbb{R}$ be an open interval and $y, z \in C(I)$ (or $y, z \in C\left(I, \mathbb{R}^{2}\right)$ ) be linearly independent functions. We denote by $H(y, z)$ the linear hull of $\{y, z\}$ over $\mathbb{R}$. We have:

Theorem 2.1 (Wronskian separation principle for scalar functions). Let $y, z \in C^{1}(I)$ be two functions. We suppose that, $W(y, z)(x) \neq 0$, for all $x \in I$. Let $u, v \in H(y, z)$ be two linearly independent functions. Then the zeros of $u, v$ separate each other.

Proof. Since $W(y, z)(x) \neq 0$, for all $x \in I$, implies that $W(u, v)(x) \neq 0$, for all $x \in I$, the proof follows from the Wronskian Lemma.

Theorem 2.2 (Wronskian separation theorem for vectorial functions). Let $y, z \in$ $C\left(I, \mathbb{R}^{2}\right)$ be two vectorial functions. We suppose that:

(1) $W(y, z)(x):=\left|\begin{array}{ll}y_{1} & y_{2} \\ z_{1} & z_{2}\end{array}\right|(x) \neq 0$, for all $x \in I$.

(2) The zeros of $y_{1}$ and $y_{2}$, and $z_{1}$ and $z_{2}$ separate each other.

Then the zeros of $y_{1}$ and $z_{1}$, and $y_{2}$ and $z_{2}$ separate each other. Moreover, if the zero of each two linearly independent element of $H\left(y_{1}, y_{2}\right)$ and of $H\left(z_{1}, z_{2}\right)$ separate each other, then if $u \in H(y, z)$ is a nontrivial element, the zeros of $u_{1}$ and $u_{2}$ separate each other.

Proof. First of all we prove that the zeros of $y_{1}$ and $y_{2}$, and $z_{1}$ and $z_{2}$ separate each other. Let us prove this property for $y_{1}$ and $z_{1}$. Let, for example, $x_{1}, x_{2} \in$ $Z_{y_{1}}$ be two consecutive zeros. Then, from $W(y, z)(x) \neq 0$, for all $x \in I$, it follows that sgn $y_{2}\left(x_{1}\right) z_{1}\left(x_{1}\right)=\operatorname{sgn} y_{2}\left(x_{2}\right) z_{1}\left(x_{2}\right)$. But $y_{2}\left(x_{1}\right) y_{2}\left(x_{2}\right)<0$. So, from Bolzano Theorem, $\left.Z_{z_{1}} \cap\right] x_{1}, x_{2}[\neq 0$. Now, let us prove the second part of the conclusions of the theorem. Let $v \in H(y, z)$ be such that the functions $u, v$ are linearly independent. Then, $W(y, z)(x) \neq 0$, for all $x \in I$, implies that $W(u, v)(x) \neq 0$, for all $x \in I$. The proof follows from the first part of conclusions of the theorem.

Remark 2.3. From Theorem 2.1 and Theorem 2.2 it follows the following result:

Theorem 2.4. Let $y, z \in C^{1}(I)$ be as in Theorem 2.1. If the zeros of $y^{\prime}$ and $z^{\prime}$ separate each other, then the zeros of $y$ and $y^{\prime}$, and $z$ and $z^{\prime}$ separate each other. 


\section{Linear and Homogeneous Second Order Differential Equations}

In this section we present some well known results in the zero separation theory for linear and homogeneous second order differential equations as consequence of Wronskian Lemma and Wronskian Theorems.

For $p, q, p_{i}, q_{i} \in C(I), i=1,2$, we consider the differential equation

$$
y^{\prime \prime}+p y^{\prime}+q y=0
$$

and the system of differential equations

$$
\begin{aligned}
& y^{\prime}+p_{1} y+q_{1} z=0 \\
& z^{\prime}+p_{2} y+q_{2} z=0
\end{aligned}
$$

The basic results in zero separation theory for (3.1) and (3.2) are the following.

Theorem 3.1. Let $y, z$ be two linearly independent solutions of (3.1). Then we have:

(i) (Sturm) The zeros of $y$ and $z$ separate each other.

(ii) (Butlewski [12]) If $q(x) \neq 0$, for all $x \in I$, then the zeros of $y^{\prime}$ and $z^{\prime}$ separate each other.

(iii) (Butlewski [12]) If $p, q \in C^{1}(I)$ and $\left[q^{2}+p^{\prime} q-q^{\prime} p\right](x) \neq 0$ for all $x \in I$, then the zeros of $y^{\prime \prime}$ and $z^{\prime \prime}$ separate each other.

Proof. (i). Follows from Wronskian Lemma.

(ii). Since, $W\left(y^{\prime}, z^{\prime}\right)=q W(y, z)$, the proof follows from Wronskian Lemma.

(iii). Since, $W\left(y^{\prime \prime}, z^{\prime \prime}\right)=\left(q^{2}+p^{\prime} q-p q^{\prime}\right) W(y, z)$, the proof follows from Wronskian Lemma.

Theorem 3.2 (Nicolescu [42] and Butlewski [12]). Let y be a nontrivial solution of (3.1). We have:

(i) If $q(x) \neq 0$, for all $x \in I$, then the zeros of $y$ and $y^{\prime}$ separate each other.

(ii) If $p, q \in C^{1}(I), p(x) \neq 0$ and $\left[q^{2}+p^{\prime} q-p q^{\prime}\right](x) \neq 0$, for all $x \in I$, then the zeros of $y$ and $y^{\prime \prime}$ separate each other.

(iii) If $p, q \in C^{1}(I), q(x) \neq 0$ and $\left[q^{2}+p^{\prime} q-q^{\prime} p\right](x) \neq 0$, for all $x \in I$, then the zeros of $y^{\prime}$ and $y^{\prime \prime}$ separate each other.

Proof. Let $u, v$ be two linearly independent solutions of (3.1). Then $y \in H(u, v)$.

(i). Since $W(u, v)(x) \neq 0$ and $W\left(u^{\prime}, v^{\prime}\right)(x) \neq 0$, for all $x \in I$, by Theorem 3.1, the zeros of $u, v$, and $u^{\prime}$ and $v^{\prime}$ separate each other. Now the proof follows from Remark 3.5.

$(i i)+($ iii $)$. The proof follows from Theorem 3.1 and Theorem 2.2.

Theorem 3.3 (Nicolescu [42] and Butlewski [12]). Let $\left(y_{1}, z_{1}\right)$ and $\left(y_{2}, z_{2}\right)$ be two linearly independent solutions of (3.2). Then we have:

(i) If $q_{1}(x) \neq 0$, for all $x \in I$, then the zeros of $y_{1}$ and $y_{2}$ separate each other.

(ii) If $p_{2}(x) \neq 0$, for all $x \in I$, then the zeros of $z_{1}$ and $z_{2}$ separate each other.

(iii) If $p_{1}, q_{1} \in C^{1}(I)$ and $q_{1}\left(p_{1} q_{2}-p_{2} q_{1}\right)(x)+\left(q_{1} p_{1}^{\prime}-p_{1} q_{1}^{\prime}\right)(x) \neq 0$, for all $x \in I$, then the zeros of $y_{1}^{\prime}$ and $y_{2}^{\prime}$ separate each other.

(iv) If $p_{2}, q_{2} \in C^{1}(I)$ and $p_{2}\left(p_{1} q_{2}-p_{2} q_{1}\right)(x)+\left(p_{2} q_{2}^{\prime}-q_{2} p_{2}^{\prime}\right)(x) \neq 0$, for all $x \in I$, then the zeros of $z_{1}^{\prime}$ and $z_{2}^{\prime}$ separate each other. 
Proof. (i). $W\left(y_{1}, y_{2}\right)(x)=-q_{1} W\left(\left(y_{1}, z_{1}\right),\left(y_{2}, z_{2}\right)\right)(x) \neq 0$, for all $x \in I$. The proof follows from Wronskian Lemma.

(ii). $W\left(z_{1}, z_{2}\right)(x)=p_{2} W\left(\left(y_{1}, z_{1}\right),\left(y_{2}, z_{2}\right)\right)(x) \neq 0$, for all $x \in I$. The proof follows from Wronskian Lemma.

(iii). $W\left(y_{1}^{\prime}, y_{2}^{\prime}\right)=\left[q_{1}\left(p_{1} q_{2}-p_{2} q_{1}\right)+q_{1} p_{1}^{\prime}-p_{1} q_{1}^{\prime}\right](x) W\left(\left(y_{1}, z_{1}\right),\left(y_{2}, z_{2}\right)\right)(x) \neq 0$, for all $x \in I$. The proof follows from Wronskian Lemma.

(iv). $W\left(z_{1}^{\prime}, z_{2}^{\prime}\right)=\left[p_{2}\left(p_{1} q_{2}-p_{2} q_{1}\right)+p_{2} q_{2}^{\prime}-q_{2} p_{2}^{\prime}\right](x) W\left(\left(y_{1}, z_{1}\right),\left(y_{2}, z_{2}\right)\right)(x) \neq 0$, for all $x \in I$. The proof follows from Wronskian Lemma.

Theorem 3.4. Let $(y, z)$ be a nontrivial solution of (3.2). Then we have:

(i) (Nicolescu) If $q_{1}(x) \neq 0$ and $p_{2}(x) \neq 0$, for all $x \in I$, then the zeros of $y$ and $z$ separate each other.

(ii) (Butlewski) If $p_{i}, q_{i} \in C^{1}(I), i=1,2,\left(p_{1} q_{2}-p_{2} q_{1}\right)(x) \neq 0,\left[q_{1}\left(p_{1} q_{2}-p_{2} q_{1}\right)+\right.$ $\left.q_{1} p_{1}^{\prime}-p_{1} q_{1}^{\prime}\right](x) \neq 0$ and $\left[p_{2}\left(p_{1} q_{2}-p_{2} q_{1}\right)+p_{2} q_{2}^{\prime}-q_{2} p_{2}^{\prime}\right](x) \neq 0$, for all $x \in I$, then the zeros of $y^{\prime}$ and $z^{\prime}$ separate each other.

Proof. Let $\left(y_{1}, z_{1}\right)$ and $\left(y_{2}, z_{2}\right)$ be two linearly independent solutions of (3.2). Then, $(y, z) \in H\left(\left(y_{1}, z_{1}\right),\left(y_{2}, z_{2}\right)\right)$.

(i). Since, $W\left(\left(y_{1}, z_{1}\right),\left(y_{2}, z_{2}\right)\right)(x) \neq 0$, for all $x \in I$, the proof follows from Theorem 3.3 and Theorem 2.2.

(ii). Since, $W\left(\left(y_{1}^{\prime}, z_{1}^{\prime}\right),\left(y_{2}^{\prime}, z_{2}^{\prime}\right)\right)(x)=\left(p_{1} q_{2}-p_{2} q_{1}\right)(x) W\left(\left(y_{1}, z_{1}\right),\left(y_{2}, z_{2}\right)\right)(x) \neq 0$, for all $x \in I$, the proof follows from Theorem 3.3 and Theorem 2.1.

Remark 3.5. Let us consider the quasilinear equation

$$
y^{\prime \prime}+p\left(y^{\prime}, y, x\right) y^{\prime}+q\left(y^{\prime}, y, x\right) y=0
$$

and the quasilinear system

$$
\begin{aligned}
& y^{\prime}+p_{1}(y, z, x) y+q_{1}(y, z, x) z=0 \\
& z^{\prime}+p_{2}(y, z, x) y+q_{2}(y, z, x) z=0
\end{aligned}
$$

From the Theorem 3.2 and Theorem 3.4 we have the following results:

Theorem 3.6. We suppose that:

(1) $p, q \in C\left(\mathbb{R}^{2} \times I\right)$.

(2) $q(t) \neq 0$, for all $t \in \mathbb{R}^{2} \times I$.

If $y \in C^{2}(I)$ is a nontrivial solution of (3.3), then the zeros of $y$ and $y^{\prime}$ separate each other.

Proof. We remark that $y$ is a solution of the following linear equation

$$
u^{\prime \prime}+p\left(y^{\prime}, y, x\right) u^{\prime}+q\left(y^{\prime}, y, x\right) u=0 .
$$

Theorem 3.7. We suppose that:

(1) $p_{i}, q_{i} \in C\left(\mathbb{R}^{2} \times I\right), i=1,2$.

(2) $q_{1}(t) \neq 0, p_{2}(t) \neq 0$, for all $t \in \mathbb{R}^{2} \times I$.

If $(y, z) \in C^{1}\left(I, \mathbb{R}^{2}\right)$ is a nontrivial solution of (3.4), then the zeros of $y$ and $z$ separate each other. 
Proof. We remark that $(y, z)$ is a solution of the following linear system

$$
\begin{aligned}
& u^{\prime}+p_{1}(y, z, x) u+q_{1}(y, z, x) v=0, \\
& v^{\prime}+p_{2}(y, z, x) u+q_{2}(y, z, x) v=0 .
\end{aligned}
$$

Remark 3.8. For similar results, as above, using linearization principle, see [52].

\section{Nonlinear Equations in a Normal Form}

For $f, p, q \in C\left(\mathbb{R}^{2} \times I\right)$ with, $f(0,0, x)=0, p(0,0, x)=0$ and $q(0,0, x)=0$, for all $x \in I$, we consider the following equation

$$
y^{\prime \prime}+f\left(y^{\prime}, y, x\right)=0
$$

and the following system,

$$
\begin{aligned}
& y^{\prime}+p(y, z, x)=0, \\
& z^{\prime}+q(y, z, x)=0 .
\end{aligned}
$$

In this case we have the following results.

Theorem 4.1. We suppose that:

(1) For all $x \in I$, sgn $f(0, t, x)=\operatorname{sgn} t$, for all $t \in \mathbb{R}$ or $\operatorname{sgn} f(0, t, x)=-\operatorname{sgn} t$, for all $t \in \mathbb{R}$.

(2) All Cauchy problems for (4.1) have at most a solution.

In this conditions if $y$ is a nontrivial solution of (4.1), then the zeros of $y$ and $y^{\prime}$ separate each other.

Proof. First of all we remark that, in the conditions of our theorem, the zeros of $y$ and $y^{\prime}$ are all simple. Now, let $x_{1}, x_{2} \in I$ be two consecutive zeros of $y^{\prime}$. For example, for the first part of (1), we have that,

$$
\operatorname{sgn} y^{\prime \prime}\left(x_{i}\right)=-\operatorname{sgn} y\left(x_{i}\right), i=1,2 .
$$

But $y^{\prime \prime}\left(x_{1}\right) y^{\prime \prime}\left(x_{2}\right)<0$. from this we have that $y\left(x_{1}\right) y\left(x_{2}\right)<0$. Now the proof follows from Bolzano Theorem.

Example 4.2 (see [1]). Let us consider the following nonlinear equation

$$
y^{\prime \prime}+y^{\prime 2}+e^{t} y^{3}=0, t \in \mathbb{R}_{+} .
$$

This equation satisfies the condition in Theorem 4.1. So, if $y \in C^{2}\left(\mathbb{R}_{+}\right)$is a solution of this equation, then the zeros of $y$ and $y^{\prime}$ separate each other.

A similar result we have for the equation (see [57])

$$
y^{\prime \prime}+a\left|y^{\prime}\right| y^{\prime}+b y=0, a, b \in \mathbb{R}_{+}^{*} .
$$

In a similar way we have,

Theorem 4.3. We suppose that: 
(1) For all $x \in I$, sgn $p(0, t, x)=$ sgn $t$, for all $t \in \mathbb{R}$ and $\operatorname{sgn} q(t, 0, x)=$ sgn $t$, for all $t \in \mathbb{R}_{+}$.

(2) All Cauchy problems for (4.2) have at most a solution.

Then, if $(y, z) \in C^{1}\left(I, \mathbb{R}^{2}\right)$ is a solution of (4.2), then the zeros of $y$ and $z$ separate each other.

\section{Homogeneous Nonlinear Second Order Differential Equations}

Let $F, G \in C\left(\mathbb{R}^{3} \times I\right)$ be two functions with $F(0,0,0, x)=0$ and $G(0,0,0, x)=0$, for all $x \in I$. We consider the following differential equation

$$
F\left(y^{\prime \prime}, y^{\prime}, y, x\right)=0
$$

and the following system of differential equations

$$
\begin{aligned}
& F\left(y^{\prime}, y, z, x\right)=0, \\
& G\left(z^{\prime}, y, z, x\right)=0 .
\end{aligned}
$$

We have the following results:

Theorem 5.1 (Tonelli [63]; see also [50] and [37]). We suppose that:

(1) For each $x \in I$, the function, $F(\cdot, \cdot, \cdot, x): \mathbb{R}^{3} \rightarrow \mathbb{R}$ is a homogeneous function.

(2) All Cauchy problems for (5.1) have at most a solution.

In this conditions, if $y_{1}$ and $y_{2}$ are two linearly independent solutions of (5.1), then the zeros of $y_{1}$ and $y_{2}$ separate each other.

Proof. First we remark that, $y=0$ is a solution of (5.1). If $y$ is a nontrivial solution of (5.1), then the zeros of $y$ are simple and if $y_{1}$ and $y_{2}$ are two solutions such that $Z_{y_{1}} \cap Z_{y_{2}} \neq \emptyset$, then $y_{1}$ and $y_{2}$ are linearly dependent. Now let $y_{1}$ and $y_{2}$ be two linearly independent solutions. Let for example $x_{1}, x_{2} \in Z_{y_{1}}$ be two consecutive zeros. If $\left.Z_{y_{2}} \cap\right] x_{1}, x_{2}\left[=\emptyset\right.$, then, $y_{2}(x) \neq 0$, for all $x \in\left[x_{1}, x_{2}\right]$. Since if $y$ is a solution then, $-y$ is also a solution, we can suppose that: $y_{1}(x)>0$, for all $\left.x \in\right] x_{1}, x_{2}$ [ and $y_{2}(x)>0$, for all $x \in\left[x_{1}, x_{2}\right]$. Now the proof follows from Tonelli Lemma.

Theorem 5.2 (Tonelli [63]; see also [28]). We suppose that:

(1) For each $x \in I, F(\cdot, \cdot, \cdot, x): \mathbb{R}^{3} \rightarrow \mathbb{R}$ is a homogeneous function.

(2) If $y_{1}$ and $y_{2}$ are solutions of (5.1) and for some $x_{0} \in I, y_{1}\left(x_{0}\right)=y_{2}\left(x_{0}\right)>0$ and $y_{1}^{\prime}\left(x_{0}\right)=y_{2}^{\prime}\left(x_{0}\right)$, then, $y_{1}=y_{2}$.

In these conditions, if $y_{1}$ and $y_{2}$ are two linearly independent solutions of (5.1) then:

(i) if $x_{1}, x_{2} \in I$ are two consecutive zeros of $y_{1}$, then $Z_{y_{2}} \cap\left[x_{1}, x_{2}\right] \neq \emptyset$;

(ii) if $x_{1}, x_{2} \in I$ are two consecutive zeros of $y_{2}$, then $Z_{y_{1}} \cap\left[x_{1}, x_{2}\right] \neq \emptyset$.

Proof. The proof follows from Tonelli Lemma.

Theorem 5.3 (see [28]). We suppose that:

(1) For each $x \in I, F(\cdot, \cdot, \cdot, x): \mathbb{R}^{3} \rightarrow \mathbb{R}$ is a homogeneous function.

(2) If $y_{1}$ and $y_{2}$ are two solutions of (5.1) and for some $x_{0} \in I, y_{1}^{\prime}\left(x_{0}\right)=y_{2}^{\prime}\left(x_{0}\right)>0$ and $y_{1}^{\prime \prime}\left(x_{0}\right)=y_{2}^{\prime \prime}\left(x_{0}\right)$, then, $y_{1}=y_{2}$. 
In these conditions, if $y_{1}$ and $y_{2}$ are two linearly independent solutions of (5.1) then:

(i) if $x_{1}, x_{2} \in I$ are two consecutive zeros of $y_{1}^{\prime}$, then $Z_{y_{2}^{\prime}} \cap\left[x_{1}, x_{2}\right] \neq \emptyset$;

(ii) if $x_{1}, x_{2} \in I$ are two consecutive zeros of $y_{2}^{\prime}$, then $Z_{y_{1}^{\prime}} \cap\left[x_{1}, x_{2}\right] \neq \emptyset$.

Proof. The proof follows from Tonelli Lemma (see [28]).

Theorem 5.4. We suppose that:

(1) For each $x \in I$, the functions $F, G: \mathbb{R}^{3} \rightarrow \mathbb{R}$ are homogeneous.

(2) If $\left(y_{1}, z_{1}\right)$ and $\left(y_{2}, z_{2}\right)$ are two solutions of (5.2), then:

(a) if for some $x_{0} \in I, y_{1}\left(x_{0}\right)=y_{2}\left(x_{0}\right)$ and $y_{1}^{\prime}\left(x_{0}\right)=y_{2}^{\prime}\left(x_{0}\right)$, then, $\left(y_{1}, z_{1}\right)=$ $\left(y_{2}, z_{2}\right)$

(b) if for some $x_{0} \in I, z_{1}\left(x_{0}\right)=z_{2}\left(x_{0}\right)$ and $z_{1}^{\prime}\left(x_{0}\right)=z_{2}^{\prime}\left(x_{0}\right)$, then, $\left(y_{1}, z_{1}\right)=$ $\left(y_{2}, z_{2}\right)$.

In the above conditions, if $\left(y_{1}, z_{1}\right)$ and $\left(y_{2}, z_{2}\right)$ are two linearly independent solutions of (5.2), then the zeros of $y_{1}$ and $y_{2}$, and of $z_{1}$ and $z_{2}$ separate each other.

Proof. The proof follows from Tonelli Lemma.

\section{Some Research Directions}

6.1. Zero separation theory for nonlinear second order differential equations

Problem 6.1. To complete the results of this paper with some results for (see Abstract):

(i) Problem 1: (2) and (3);

(ii) Problem 2: (3);

(iii) Problem 3: (2);

(iv) Problem 4: (3) and (4);

References: [1], [28], [31], [32], [34], [49], [50], [52], [67], ..

6.2. Problem 6.2. To use the implicit function theorem in [11] to study the uniqueness of solution for the following problem:

$$
F\left(y^{\prime \prime}, y^{\prime}, y, x\right)=0, y^{\prime}\left(x_{0}\right)=y_{0}^{\prime}, y^{\prime \prime}\left(x_{0}\right)=y_{0}^{\prime \prime} .
$$

6.3. Zero separation principles for the solutions of two second order differential equations

Let $p_{i}, q_{i} \in C(I), i=1,2$. We consider the following differential equations:

$$
\begin{aligned}
& y^{\prime \prime}+p_{1} y^{\prime}+q_{1} y=0 \\
& z^{\prime \prime}+p_{2} z^{\prime}+q_{2} z=0
\end{aligned}
$$

Let $y_{1}$ and $y_{2}$ be two linearly independent solutions of (6.1), and $z_{1}$ and $z_{2}$ be two linearly independent solutions of (6.2). From the Theorem 2.2 we have the following result:

If, $W\left(\left(y_{1}, z_{1}\right),\left(y_{2}, z_{2}\right)\right)(x) \neq 0$, for all $x \in I$, and $y$ is a nontrivial solution of (6.1) and $z$ is a nontrivial solution of (6.2) such that, $(y, z) \in H\left(\left(y_{1}, z_{1}\right),\left(y_{2}, z_{2}\right)\right)$, then the zeros of $y$ and $z$ separate each other.

From this result the following problem appears. 
Problem 6.3. Let $y_{1}$ and $y_{2}$ be two linearly independent solutions of (6.1), and $z_{1}$ and $z_{2}$ be two linearly independent solutions of (6.2). In which conditions we have that,

$$
W\left(\left(y_{1}, z_{1}\right),\left(y_{2}, z_{2}\right)\right)(x) \neq 0, \text { for all } x \in I ?
$$

Each solution for this problem has an impact in the zero separation theory for some special functions: Bessel functions, Legendre functions, Mathieu functions, ...

References: [59], [60], [38], [32], [57], [62], .. .

6.4. Wronskian Lemma and Wronskian Theorems techniques in zero separation of polynomial functions

The following Markov Theorem is well known: If the zeros of the polynomial functions $P$ and $Q$ are all real and separate each other, then the zeros of $P^{\prime}$ and $Q^{\prime}$ separate each other.

In [16], F. Constantinescu proves this theorem using the Sturm separation theorem.

Problem 6.4. To use Wronskian Lemma and Wronskian Theorems in the zero separation theory of polynomial functions.

References: [16], [18], [34], [43], [51], [53], [65], [66], ..

6.5. Problem 6.5. To use the angular function of a planar vector field techniques in zero separation theory for nonlinear second order equations.

References: [34], [4], [56], [13], [41], ..

6.6. Problem 6.6. To use the Borůvka theory of functions defined in terms of zeros of solutions of linear second order equations to study the zero distance functions.

References: [9], [10], [5], [21], [41], [36], ...

6.7. Zero separation theory in the case of linear and homogeneous second order differential equations in the complex domain

Problem 6.7. To give a good notion of zero separation of two complex functions. In terms of this notion, to construct a Sturm zero separation theory in the complex domain.

References: [25], [26], [29], [33], [1], [6], [7], [14], [62], ..

6.8. Problem 6.8. The notion of the category of ordinary linear differential equations is given in [41]. An object of this category is a linear differential equation and a morphism for two objects is a global transformation. The problem is to consider some subcategories of this category which are relevant for zero point theory of solutions of differential equations.

\section{References}

[1] Abdullah, H.Kh., On the oscillation of second order nonlinear differential equations, Inter. J. Appl. Math. Research, 3(2014), no. 1, 1-6.

[2] Agarwal, R.P., Grace, S.R., O'Regan, D., Linearization of second order superlinear oscillation theorems, Math. Computer Modelling, 39(2004), 1165-1183.

[3] Aharonov, D., Elias, U., On singular Sturm theorems, arXiv: 1708.06168v1, 2017.

[4] Amann, H., Ordinary Differential Equations, de Gruyter, 1990. 
[5] Bailey, P., Waltman, P., On the distance between consecutive zeros for second order differential equations, J. Math. Anal. Appl., 14(1966), 23-30.

[6] Barbu, V., Differential Equations, Springer, 2016.

[7] Barrett, J.H., Second order complex differential equations with a real independent variable, Pacific J. Math., 8(1958), 187-200.

[8] Barrett, L.C., Bendixen, G.E., Separation and interlacing theorems, Quart. Appl. Math., 23(1965), no. 1, 69-78.

[9] Borůvka, O., On central dispersions of the differential equations $y^{\prime \prime}=q(t) y$ with periodic coefficients, Lecture Notes in Math., 415(1974), 47-61.

[10] Borůvka, O., Linear differential transformations of the second order, The English Universities Press, London, 1971.

[11] Buică, A., Rus, I.A., Şerban, M.A., Zero point principle of ball-near identity operators and applications to implicit operator problem, (to appear).

[12] Butlewski, Z., Sur les zéros des intégrales réelles des equations différentielles linéaires, Mathematica, 17(1941), 85-110.

[13] Chicone, C., Ordinary Differential Equations with Applications, Springer, 1999.

[14] Chuaqui, M., Gröhn, J., Heittokangas, J., Rättyä, J., Zero separation results for solutions of second order linear differential equations, Advances in Math., 245(2013), 382-422.

[15] Coddington, E.A., Levinson, N., Theory of Ordinary Differential Equations, McGrawHill, New York, 1955.

[16] Constantinescu, F., A new proof of a theorem of V.A. Markov using a theorem of Sturm, (Russian), Uspehi Mat. Nauk, 12(1957), no. 6, 147-148.

[17] Corduneanu, C., Principles of Differential and Integral Equations, Chelsea Publ. Company, New York, 1977.

[18] Craven, T., Csordas, G., On the betweenness condition of Rolle's theorem, Rocky Mountain J. Math., 15(1985), no. 3, 721-728.

[19] Cuculescu, I., Separarea zerourilor unei perechi de soluţii a unui sistem de ecuaţii differenţiale, G.M.F. (Bucureşti), 5(1953), 194-195.

[20] Drakhlin, M.R., On the zeros of solutions of a Riccati equation, Izv. Vyssh. Uchebn. Zaved. Mat., 1965, no. 5, 58-64.

[21] Foiaş, C., Gussi, G., Poenaru, V., Despre problema polilocală la ecuaţiile diferenţiale liniare de ordinul al doilea, Bul. Ştiinţific, Mat. Fiz., 7(1955), no. 3, 699-721.

[22] Haimovici, A., Ecuaţii diferenţiale şi ecuaţii integrale, Ed. Didactică şi Pedagogică, Bucureşti, 1965.

[23] Halanay, A., Differential Equations: Stability, Oscillations, Time Lags, Acad. Press, New York, 1966.

[24] Hartman, P., Ordinary Differential Equations, John Wiley and Sons, New York, 1964.

[25] Hille, E., Lectures on Ordinary Differential Equations, Addison-Wesley Publ. Company, 1969.

[26] Hille, E., Ordinary Differential Equations in the Complex Domain, John Wiley and Sons, New York, 1976.

[27] Hirsch, M.W., Smale, S., Devaney, R.L., Differential Equations, Dynamical Systems, and an Introduction to Chaos, Elsevier, 2004.

[28] Ilea, V., Otrocol, D., Rus, I.A., Some properties of solutions of the homogeneous nonlinear second order differential equations, Mathematica, 57(2015), no. 1-2, 38-43. 
[29] Ilyashenko, Y., Yakovenko, S., Lectures on Analytic Differential Equations, AMS, 2003.

[30] Ionescu, D.V., Ecuaţii diferenţiale şi integrale, Ed. Didactică şi Pedagogică, Bucureşti, 1972 .

[31] Jordan, D.W., Smith, P., Nonlinear Ordinary Differential Equations, Oxford Univ. Press, 2007.

[32] Kamke, E., Differentialgleichungen, I, Leipzig, 1959.

[33] Kou, K.I., Xia, Y.-H., Linear quaternion differential equations: basic theory and fundamental results, arXiv:1510.02224v5, 2017.

[34] Krasnoselskii, M.A., Perov, A.I., Povolockii, A.I., Zabrejko, P.P., Plane Vector Fields, Acad. Press, New York, 1966 (Moscow (1963), Berlin (1966)).

[35] Lefschetz, S., Differential Equations: Geometric Theory, Interscience Publ., New York, 1957.

[36] Leighton, W., The conjugacy function, Proc. Amer. Math. Soc., 24(1970), 820-823.

[37] Makay, G., A simple proof for Sturm's separation theorem, Amer. Math. Monthly, 99(1992), no. 3, 218-219.

[38] Marx, I., On the structure of recurrence relations II, Michigan Math. J., 2(1953), 99-103.

[39] Mureşan, A.S., Tonelli's Lemma and applications, Carpathian J. Math., 28(2012), no. $1,103-110$.

[40] Nemytskii, V., Stepanov, V., Qualitative Theory of Differential Equations, Princeton Univ. Press, Princeton, 1960 (Moscow, 1949).

[41] Neuman, F., Global Properties of Linear Ordinary Differential Equations, Kluwer, 1991.

[42] Nicolescu, M., Sur le théorème de Sturm, Mathematica (Cluj), 1(1929), 111-114.

[43] Pinkus, A., Ziegler, Z., Interlacing properties of the zeros of the error functions in best $L^{p}$-approximations, J. Appr. Theory, 27(1979), 1-18.

[44] Polyanin, A.D., Zaitsev, V.F., Handbook of Exact Solutions for Ordinary Differential Equations, Chapman and Hall/CRC, 2002.

[45] Precup, R., Ordinary Differential Equations, de Gruyter, 2018.

[46] Protter, M.H., Weinberger, H.F., Maximum Principles in Differential Equations, Springer, 1984.

[47] Reid, W.T., Sturm Theory for Ordinary Differential Equations, Springer, 1980.

[48] Rus, I.A., Teoreme de tip Sturm, Studia Univ. Babeş-Bolyai, 1(1961), no. 1, 131-136.

[49] Rus, I.A., Asupra unor theoreme de tip Sturm, Studia Univ. Babeş-Bolyai, Mat.-Fiz., 2(1962), 33-36.

[50] Rus, I.A., Asupra rădăcinilor componentelor soluţiilor unui sistem de două ecuaţii diferenţiale de ordinul întâi, Studii şi Cercetări de Matematică (Cluj), 14(1963), no. 1, 151-156.

[51] Rus, I.A., Familii de funcţii cu proprietatea lui Sturm, Studia Univ. Babeş-Bolyai, Mat.Fiz., 1(1966), 37-40.

[52] Rus, I.A., Câteva proprietăti ale zerourilor componentelor soluţiilor unui sistem de două ecuaţii diferenţiale neliniare de ordinul I, Studii şi Cercetări Matematice (Bucureşti), 18(1966), no. 10, 1549-1553.

[53] Rus, I.A., Open problem Nr. 5, Glasnik Matematički, 4(1969), no. 1, 170.

[54] Rus, I.A., Separation theorems for the zeros of some real functions, Mathematica, 27(1985), no. 1, 43-46. 
[55] Rus, I.A., Ecuaţii diferenţiale, ecuaţii integrale şi sisteme dinamice, Transilvania Press, Cluj-Napoca, 1996.

[56] Sadyrbaev, F., Multiplicity of solution for two-point boundary value problems with asymptotically asymmetric nonlinearities, Univ. Catholique de Louvain, no. 41, 1994.

[57] Sansone, G., Equazioni differenziali nel campo reale, Zanichelli, Bologna, I(1940), II(1949).

[58] Sansone, G., Conti, R., Equazioni differenziali non lineari, Ed. Cremonesse, Roma, 1956.

[59] Segura, J., The zeros of special functions from a fixed point method, SIAM J. Numer. Anal., 40(2002), no. 1, 114-133.

[60] Segura, J., Some analytical and numerical consequences of Sturm theorems, Adv. Dyn. Syst. Appl., 8(2013), no. 2, 327-347.

[61] Swanson, C.A., Comparison and Oscillation Theory of Linear Differential Equations, Acad. Press, New York, 1968.

[62] Teodorescu, N., Olariu, V., Ecuaţii diferenţiale şi cu derivate parţiale, Vol. I, Ed. Tehnică, Bucureşti, 1978.

[63] Tonelli, L., Un'osservazione su di un teorema di Sturm, Boll. UMI, 6(1927), 126-128.

[64] Tricomi, F., Equazioni differenziali, Scientifiche Einaudi, 1953.

[65] Vishnyakova, A., Zero separation of polynomials and hyperbolicity preserving linear operators, Shanghai, 2015.

[66] Walker, P., Separation of the zeros of polynomials, Amer. Math. Monthly, 100(1993), 272-273.

[67] Wong, J.S.W., Oscillation criteria for second order nonlinear differential equations with integrable coefficients, Proc. Amer. Math. Soc., 115(1992), no. 2, 389-395.

[68] Zwillinger, D., Handbook of Differential Equations, Acad. Press, New York, 1997.

Ioan A. Rus

Babeş-Bolyai University, Faculty of Mathematics and Computer Sciences

1, Kogălniceanu Street, 400084 Cluj-Napoca, Romania

e-mail: iarus@math.ubbcluj .ro 